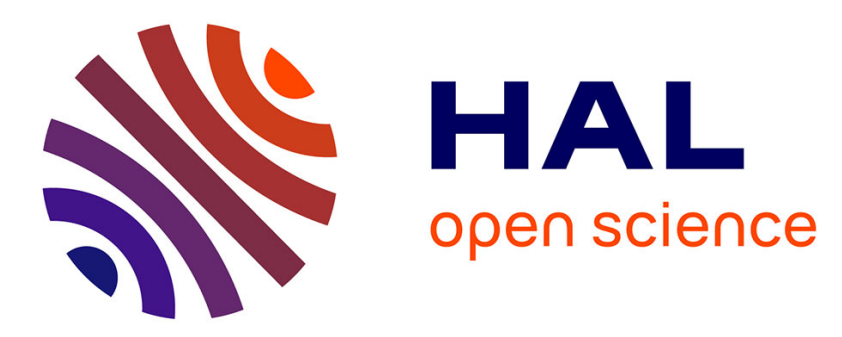

\title{
Radicals Generated in Tetramolecular Guanine Quadruplexes by Photoionization: Spectral and Dynamical Features
}

Akos Banyasz, Evangelos Balanikas, Lara Martinez-Fernandez, Gérard Baldacchino, Thierry Douki, Roberto Improta, Dimitra Markovitsi

\section{To cite this version:}

Akos Banyasz, Evangelos Balanikas, Lara Martinez-Fernandez, Gérard Baldacchino, Thierry Douki, et al.. Radicals Generated in Tetramolecular Guanine Quadruplexes by Photoionization: Spectral and Dynamical Features. Journal of Physical Chemistry B, 2019, 123 (23), pp.4950-4957. 10.1021/acs.jpcb.9b02637 . cea-02160879v2

\section{HAL Id: cea-02160879 \\ https://hal-cea.archives-ouvertes.fr/cea-02160879v2}

Submitted on 6 Aug 2020

HAL is a multi-disciplinary open access archive for the deposit and dissemination of scientific research documents, whether they are published or not. The documents may come from teaching and research institutions in France or abroad, or from public or private research centers.
L'archive ouverte pluridisciplinaire HAL, est destinée au dépôt et à la diffusion de documents scientifiques de niveau recherche, publiés ou non, émanant des établissements d'enseignement et de recherche français ou étrangers, des laboratoires publics ou privés. 


\section{Radicals Generated in Tetramolecular Guanine}

\section{Quadruplexes by Photo-ionization: Spectral and}

\section{Dynamical Features}

Akos Banyasz, ${ }^{1,2}$ Evangelos Balanikas, ${ }^{1}$ Lara Martinez-Fernandez, ${ }^{1,3}$ Gérard Baldacchino, ${ }^{1}$ Thierry Douki, ${ }^{4}$ Roberto Improta ${ }^{1,5}$ and Dimitra Markovitsi ${ }^{1} *$

${ }^{1}$ LIDYL, CEA, CNRS, Université Paris-Saclay, F-91191 Gif-sur-Yvette, France

${ }^{2}$ Univ Lyon, ENS de Lyon, CNRS UMR 5182, Université Claude Bernard Lyon 1, Laboratoire de Chimie, F-69342 Lyon, France

${ }^{3}$ Departamento de Química, Universidad Autónoma de Madrid, c/ Francisco Tomás y Valiente 7, 28049 Cantoblanco, Madrid, Spain

${ }^{4}$ Univ. Grenoble-Alpes, CEA, CNRS, SyMMES UMR 5819, Grenoble France

${ }^{5}$ Istituto Biostrutture e Bioimmagini- Consiglio Nazionale delle Ricerche, Via Mezzocannone 16, I-80134 Napoli, Italy

\section{AUTHOR INFORMATION \\ Corresponding Author \\ dimitra.markovitsi@cea.fr}


ABSTRACT: G-quadruplexes are four-stranded DNA structures playing a key role in many biological functions and promising for applications in the field of nanoelectronics. Characterizing the generation and the fate of radical cations (electron holes) within these systems is important in relation to the DNA oxidative damage and/or conductivity issues. This study focuses on guanine radicals in G-quadruplexes formed by association of four TGGGGT strands in the presence of $\mathrm{Na}^{+}$cations, (TG4T) $)_{4} / \mathrm{Na}^{+}$. Using nanosecond transient spectroscopy with $266 \mathrm{~nm}$ excitation, we quantitatively characterize hydrated ejected electrons and three types of guanine radicals. We show that, at an energy lower by $2.7 \mathrm{eV}$ than the guanine ionization potential, one-photon ionization occurs with quantum yield of $(3.5 \pm 0.5) \times 10^{-3}$. Deprotonation of the radical cations is completed within $20 \mu \mathrm{s}$, leading to the formation of $(\mathrm{G}-\mathrm{H} 2)^{\bullet}$ radicals, following a strongly non-exponential decay pattern. Within $10 \mathrm{~ms}$, the latter undergo tautomerisation to deprotonated $(\mathrm{G}-\mathrm{H} 1)^{\bullet}$ radicals. The dynamics of the various radicals determined for $(\mathrm{TG} 4 \mathrm{~T})_{4} / \mathrm{Na}^{+}$, in connection to those reported previously for telomeric Gquadruplexes TEL21/Na ${ }^{+}$, is correlated with energetic factors computed by quantum chemical methods. The faster deprotonation of radical cations in (TG4T) $)_{4} / \mathrm{Na}^{+}$compared to TEL21/Na explains that irradiation of the former does not generate 8-oxodGuo, which is readily detected by HPLC/MS in the case of TEL21/Na ${ }^{+}$. 


\section{TOC GRAPHICS}

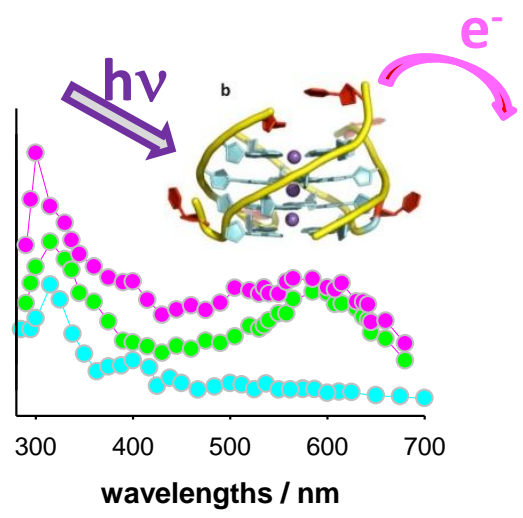

\section{KEYWORDS}

DNA; oxidative damage; photo-ionization; electron holes; radical reactivity time-resolved spectroscopy; quantum chemistry; 


\section{INTRODUCTION}

G-quadruplexes are non-canonical structures of nucleic acids formed by guanine rich DNA/RNA strands. ${ }^{1}$ Their building blocks are tetrads composed of four guanines interconnected through eight hydrogen bonds (Figure 1a) while metal ions located in the central cavity contribute to their stability. Detected recently in vivo, ${ }^{2-3}$ they play a key role in various biological functions, such as gene transcription and cell division, and are targets for cancer therapy. ${ }^{4}$ In parallel, G-quadruplexes have attracted attention for their potential applications in the field of molecular electronics. ${ }^{5-6}$ In both biological and technological fields, oxidation of guanine, which has the lowest oxidation potential among nucleobases, is a key issue. On the one hand, oxidatively generated damage may alter the functioning of G-quadruplexes within cells. ${ }^{7-8}$ On the other, nanodevices search to exploit charge transport involving electron holes. ${ }^{9-10}$ In all these cases, guanine radical cations, generated in various ways (through chemical reactions with electron donors, through electric junctions, electrochemically...) are main players. But guanine radical cations in neutral $\mathrm{pH}$ are also known to be metastable, undergoing rapid deprotonation. ${ }^{11-}$ ${ }^{13}$ Such deprotonation disrupts charge transport in guanine wires and may also modify the radical reactivity, thus affecting the types of lesions that are ultimately created in DNA. ${ }^{14-15}$
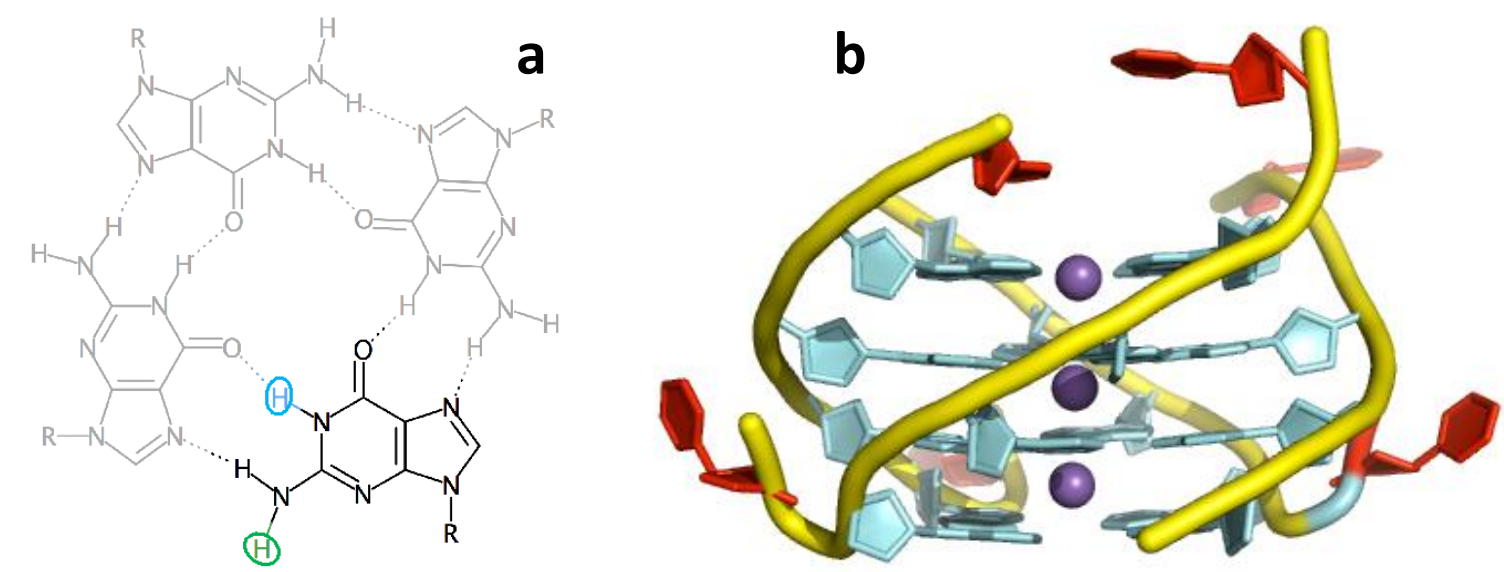
Figure 1. Schematic representation of the guanine tetrad (a) and the studied (TG4T) ${ }_{4} / \mathrm{Na}_{+}$Gquadruplex (b). Loss of the blue or the green proton shown in (a) leads to formation of $(\mathrm{G}-\mathrm{H} 1)^{\bullet}$ or $(\mathrm{G}-\mathrm{H} 2)^{\bullet}$ radical, respectively. (b) cyan: 2'-deoxyguanosines; red: thymidines; yellow: phosphoribose backbone; violet: $\mathrm{Na}^{+}$ions in the central cavity.

Within the above described context, it is very important to determine the lifetime of guanine radicals within G-quadruplexes. So far, very few studies, performed by nanosecond transient absorption, have tackled these questions. $\mathrm{Su}$ and co-workers examined guanine radicals generated in several four-stranded structures by one-electron oxidation reaction with sulfate anion. ${ }^{16}$ They drew two important conclusions: (i) radical deprotonation in G-quadruplexes is by one to two orders of magnitude slower compared to what happens in the case of the mononucleotide 2'-deoxyguanosine 5'-monophosphate (dGMP); (ii) in contrast to dGMP, for which deprotonation of the radical cation $(\mathrm{G})^{+\bullet}$ occurs at position 1 leading to $(\mathrm{G}-\mathrm{H} 1)^{\bullet}$ radical, ${ }^{11-}$ 13 deprotonation in G-quadruplexes gives rise to $(\mathrm{G}-\mathrm{H} 2)^{\bullet}$ radicals (Figure 1a). Both conclusions were qualitatively confirmed by our study on G-quadruplexes formed by folding of the human telomeric sequence GGG(TTAGGG) 3 in the presence of $\mathrm{Na}^{+}$ions $\left(\mathrm{TEL} 21 / \mathrm{Na}^{+}\right){ }^{17}$ In our approach, radicals are produced by photo-ionization of G-quadruplexes, avoiding bimolecular reactions with external molecules. By quantifying the ejected electrons and the parent radicals, we were able to follow the survival probability of the latter over five decades of time and evidence complex transformations, including $(\mathrm{G}-\mathrm{H} 2)^{\bullet} \rightarrow(\mathrm{G}-\mathrm{H} 1)^{\bullet}$ tautomerisation.

A last but not least outcome of our study on TEL21/Na ${ }^{+}$, was that photons with significantly lower energy than the ionization potential of DNA bases ${ }^{18}$ are capable of generating guanine radicals when they are directly absorbed by human telomere G-quadruplexes. ${ }^{17}$ The quantum 
yield of one-photon ionization at $266 \mathrm{~nm}$ was found to be $4.5 \times 10^{-3}$. This value is $3-4$ times higher than those, determined for DNA duplexes under the same experimental conditions, ${ }^{19-21}$ suggesting that telomeres are particularly vulnerable towards UV-induced oxidative damage.

As G-quadruplexes are known to adopt different types of topology, ${ }^{22}$ it is fundamental to understand how structural factors affect both radical generation upon direct absorption of low energy photons and characterize their lifetime. The present work focuses on G-quadruplexes formed by association of four TGGGGT strands in the presence of $\mathrm{Na}^{+}$ions, abbreviated as (TG4T) ${ }_{4} / \mathrm{Na}^{+}$(Figure 1b). Within these four-stranded scaffolds, guanines adopt a parallel arrangement in respect to the glycosidic bond while an antiparallel arrangement is encountered in TEL21/Na ${ }^{+23}$ The main tool of our study is transient absorption spectroscopy using $266 \mathrm{~nm}$ excitation with low excitation intensities $\left(\leq 2 \mathrm{MWcm}^{-2}\right)$. Three aspects of our methodology are essential: (i) The probed electrons stem solely from DNA and not from the aqueous solvent; (ii) the ejected electrons are scavenged by the phosphate groups of the buffer, preventing nucleophilic attack to DNA; ${ }^{24-25}$ (iii) the radical concentration is at least 15 times lower than that of the G-quadruplex, precluding biradical interactions.

The experimental spectra are assigned with the help of theoretical spectra computed by the Time-Dependent Differential Functional Theory (TD-DFT). In our calculations, we consider the whole G-quadruplex structure through quantum mechanics/molecular mechanics (QM/MM) approach. In this way we examine at what extent interaction within DNA multimers may modify key spectral features of various types of radicals. ${ }^{17,19-20,26}$

\section{METHODS}

\section{Experimental}

TGGGGT oligonucleotides, purified by reversed phase HPLC and tested by MALDI-TOF analysis, were purchased from Eurogentec Europe. G-quadruplexes were prepared in a dry bath 
(Eppendorf-ThermoStatplus). To this end, the lyophilized oligomer was dissolved in $2 \mathrm{~mL}$ of phosphate buffer $\left(0.15 \mathrm{~mol} \mathrm{~L}^{-1} \mathrm{NaH}_{2} \mathrm{PO}_{4}, 0.15 \mathrm{~mol} \mathrm{~L}^{-1} \mathrm{Na}_{2} \mathrm{HPO}_{4}\right.$, $\mathrm{pH}$ 7) prepared using ultrapure water delivered by a MILLIPORE (Milli-Q Integral) system; the solution was heated to $96^{\circ} \mathrm{C}$ during $5 \mathrm{~min}$, cooled to the melting point (cooling time: $1 \mathrm{~h}$ ), where the temperature was maintained for a 10 min minutes; subsequently, the solution was cooled to $4^{\circ} \mathrm{C}$ (cooling time: 2h), where it was incubated for one week. G-quadruplex formation was checked by recording the melting curve at $295 \mathrm{~nm},{ }^{27}$ shown in Figure S1.

The $\mathrm{pH}$ was measured by a HANNA Instr. Apparatus ( $\mathrm{pH} 210)$. It was adjusted to 7 by addition of a concentrated $\mathrm{NaOH}$ solution. For measurements of the G-quadruplex in $\mathrm{pH} 3$, about $30 \mu \mathrm{L}$ of the mother solution ( $\mathrm{pH}$ 7) were added into $2 \mathrm{~mL}$ of $\mathrm{NaCl}$ solution with the same ionic strength; subsequently the $\mathrm{pH}$ was adjusted by addition of a concentrated $\mathrm{HCl}$ solution. Steadystate absorption spectra were recorded using a Lambda 850 (Perkin-Elmer) spectrophotometer.

Time-resolved experiments were performed using a homemade nanosecond flash photolysis setup; the excitation source was the fourth harmonic of a Nd:YAG laser (Spectra-Physics, Quanta Ray). The excited area at the surface of the sample and the optical path-length on the excitation side were, respectively, $0.6 \times 1.0 \mathrm{~cm}^{2}$ and $0.1 \mathrm{~cm}$. The analyzing beam $(150 \mathrm{~W}$ Xe-arc lamp, OSRAM XBO) passed through the sample at right angle with respect to the exciting beam, dispersed in a Jobin-Yvon SPEX 270M monochromator, detected by a Hamamatsu R928 photomultiplier and recorded by Lecroy Waverunner oscilloscopes (6050A or 6084). Experiments on the sub $\mu$ s-scale were performed by intensifying the Xe-arc lamp via an electric discharge. Transient absorption spectra were recorded using a wavelength-by-wavelength approach. Typically, at each wavelength, a series of three successive signals, resulting from 50150 laser shots each, were recorded; if judged to be reproducible they were averaged to reduce 
the signal-to-noise ratio. Fast shutters were placed in the path of both laser and lamp beams; thus, the excitation rate was decreased from $10 \mathrm{~Hz}$ to $0.2 \mathrm{~Hz}$. The absorbance on the excitation side was $0.25 \pm 0.02$ over $0.1 \mathrm{~cm}$, corresponding to a G-quadruplex concentration of about $1.5 \times 10^{-5}$ molL $L^{-1}$. At the maximum excitation intensity $\left(2 \mathrm{MWcm}^{-2}\right)$, the concentration of ejected electrons was $\sim 10^{-6} \mathrm{molL}^{-1}$. During the experiments the temperature was kept at $23 \pm 0.5^{\circ} \mathrm{C}$. The incident pulse energy at the surface of the sample was measured using a NIST traceable pyroelectric sensor (OPHIR Nova2/PE25); it was cross-checked by measuring the absorbance of the naphthalene triplet state, whose quantum yield in cyclohexane is $0.75{ }^{28}$ Photoionization experiments were performed in Ar-purged samples. As we found that the decays on the $\mu$ s to ms domains were not affected by oxygen, transient absorption spectra were determined in aerated.

\section{Theoretical}

The minima of the ground state geometry were optimized using mixed QM/MM calculations; three of the four guanine tetrads and the inner $\mathrm{Na}^{+}$ions being described at the QM level, whereas the fourth tetrad, the backbone and outer $\mathrm{Na}^{+}$atoms at the MM level (Figure S2). The method selected for the QM region was DFT, adopting the M052X functional ${ }^{29-30}$ combined with the 6$31 \mathrm{G}(\mathrm{d})$ basis set, which has been already profitably used to describe DNA duplex and quadruplexes ${ }^{17,31-32}$. The MM part was described via Amber parm96.dat force fields. ${ }^{33}$ This is done using the ONIOM procedure, as implemented in Gaussian09. ${ }^{34}$ Solvation was taken into account for the whole QM/MM system using Polarizable Continuum Model (PCM). ${ }^{35-36}$

Using the experimental X-ray structure as starting point, ${ }^{37}$ we first optimized the cation and $(\text { PT3loc })^{26}$ and, then, starting from this minimum, the ground state geometry of the deprotonated $(\mathrm{G}-\mathrm{H} 1)^{\bullet}$ and $(\mathrm{G}-\mathrm{H} 2)^{\bullet}$ species. $^{\circ}$

Absorption spectra at the optimized minima were computed by resorting to the Time Dependent version of DFT (TD-DFT) with the same approach used in the ground state 
calculations, TD-M052X/6-31G(d) and MM (amber/parm96.dat), for the QM and MM parts, respectively. For easier comparison with the experimental results, the computed absorption spectra were simulated by convoluting each electronic transition with a Gaussian function (half width at half maximum: $0.3 \mathrm{eV}$ ) and shifted by $-0.6 \mathrm{eV}$. The -0.6 value corresponds to the shift required so that the spectrum of 2'-deoxyguanosine in water, computed at the same level of theory adopted herein, coincides with the experimental spectrum. Nevertheless, not all the sources of error (functional, incomplete basis set, lack of vibronic and thermal effects) would need the same shift. We note that smaller energy shifts $(0.2-0.3 \mathrm{eV})$ were recently used to this end in the study of radicals in a guanine-cytosine base-pair, ${ }^{38}$ the latter work used larger basis sets, not affordable for calculations on G-quadruplexes, which are much bigger systems.

\section{RESULTS AND DISCUSSION}

\section{Hydrated electrons}
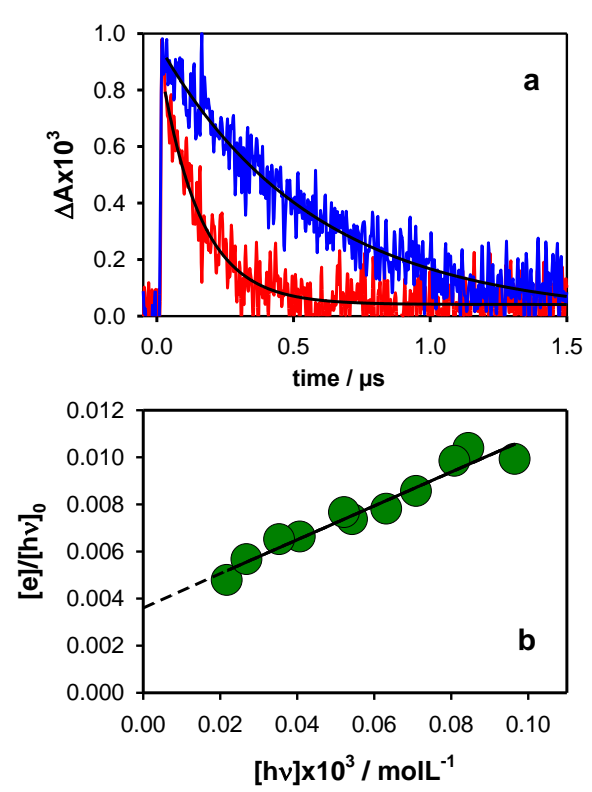
Figure 2. Quantification of ejected electrons in Ar-saturated conditions. (a) Normalized transient absorption signals recorded at $700 \mathrm{~nm}$ for (TG4T) ${ }_{4} / \mathrm{Na}^{+}$in pH 3 (red) and $\mathrm{pH} 7$ (blue); black lines correspond to fits with model functions $\mathrm{A}_{0}+\mathrm{A}_{1} \exp \left(-\mathrm{t} / \tau_{1}\right)$ with $\tau_{1}$ values of 0.15 and $0.5 \mu \mathrm{s}$, respectively. (b) Ionization curve obtained for $(\mathrm{TG} 4 \mathrm{~T})_{4} / \mathrm{Na}^{+}$in $\mathrm{pH} 7 ;\left[\mathrm{e}^{-}\right]_{0}$ and $[\mathrm{hv}]$ denote, respectively, the zero-time concentration of hydrated ejected electrons and the concentration of absorbed photons per laser pulse; $\left[\mathrm{e}^{-}\right]_{0}$ is determined using the $\mathrm{A}_{1}$ values and a molar absorption coefficient of $19700 \mathrm{~mol}^{-1} \mathrm{Lcm}^{-1} \cdot{ }^{39}$ Experimental points (circles) are fitted with the linear function $\left[\mathrm{e}^{-}\right]_{0} /[\mathrm{h} v]=\phi_{1}+\alpha[\mathrm{h} v]$ (black).

Electrons issued from photo-ionization in aqueous solution are known to be hydrated in less than 1 ps. ${ }^{40}$ Hydrated electrons exhibit a broad absorption band peaking around $720 \mathrm{~nm}$ with a maximum molar absorption coefficient $\varepsilon_{\max }$ of $19700 \mathrm{~mol}^{-1} \mathrm{Lcm}^{-1} \cdot{ }^{39}$ Based on this property, we quantify the hydrated ejected electrons by probing their transient absorption on the submicrosecond time-scale (Figure 2a). Under the same experimental conditions, no signal was detected from the neat solvent, showing that electrons stem only from the G-quadruplex. The hydrated electron decays are fitted with mono-exponential functions $A_{0}+A_{1} \exp \left(-t / \tau_{1}\right)$. The $\tau_{1}$ values found for (TG4T) $)_{4} / \mathrm{Na}^{+}$in $\mathrm{pH} 7$ and $\mathrm{pH} 3$, are, respectively, $0.5 \pm 0.1$ and $0.15 \pm 0.05 \mu \mathrm{s}$. Such short time constants result from reaction of hydrated electrons with phosphate groups and hydronium ions. ${ }^{41}$ The $\mathrm{A}_{1}$ value, combined divided by the $\varepsilon_{\max }\left(19700 \mathrm{~mol}^{-1} \mathrm{Lcm}^{-1}\right)^{39}$ provides the initial concentration of hydrated electron $\left[\mathrm{e}^{-}\right]_{0}$.

Although the excitation intensity is much lower compared to that used in previous studies on DNA photo-ionization, ${ }^{42-44}$ two-photon effects are not avoided. In order to disentangle between one- and two-photon processes, we vary the excitation intensity, resulting to different 
concentrations of absorbed photons $[\mathrm{h} v]$. Subsequently, we plot $\left[\mathrm{e}^{-}\right] /[\mathrm{h} v]$ versus $[\mathrm{h} v]$, obtaining the so-called ionization curve (Figure $2 \mathrm{~b}$ ). The fit with a linear function $\left[\mathrm{e}^{-}\right]_{0} /[\mathrm{h} v]=\varphi_{1}+\alpha[\mathrm{h} v]$ provides the quantum yield for one photon ionization $\varphi_{1}$, while the two photon ionization yield is given by the slope of the curve, $\varphi_{2}=\alpha[\mathrm{h} v]$. We note that, within the precision of our measurements, the signal intensities at 700 and $720 \mathrm{~nm}$ were practically identical. Therefore, the ionization curves were derived from the $700 \mathrm{~nm}$ decays, which are less noisy compared to those at $720 \mathrm{~nm}$.

For (TG4T) $)_{4} / \mathrm{Na}^{+}$in $\mathrm{pH} 3$, we determined solely $\left[\mathrm{e}^{-}\right]_{0}$ for a given excitation intensity in order to correlate it with that of radical cations (see below). The ionization curve shown in Figure $2 b$ was obtained for $(\mathrm{TG} 4 \mathrm{~T})_{4} / \mathrm{Na}^{+}$in $\mathrm{pH} 7$, which gives a $\varphi_{1}=(3.5 \pm 0.5) \times 10^{-3}$. This value clearly higher than those reported previously for a few model single and double helices, which falls in the range $(1-2) \times 10^{-3},{ }^{19-21,45}$ but lower than that determined for TEL21/ $\mathrm{Na}^{+}, \varphi_{1}=(4.5 \pm 0.6) \times 10^{-3} .17$

\section{Radicals}

As we saw previously, experiments on the sub-microsecond time-scale provide quantification of the hydrated ejected electrons. After their decay, the time-resolved absorption spectra observed for (TG4T) $)_{4} / \mathrm{Na}^{+}$are expected to correspond to radicals issued from photo-ionization and, possibly, to photo-reaction products.

The spectral identification of the various types of radicals, e.g. the radical cation $(G)^{+\bullet}$ and deprotonated radicals $(\mathrm{G}-\mathrm{H} 1)^{\bullet}$ and $(\mathrm{G}-\mathrm{H} 2)^{\bullet}$, including their quantification via their molar absorption coefficients, associated with $\left[\mathrm{e}^{-}\right]_{0}$, allows us to determine their survival probability. Before presenting the radical spectra obtained for the G-quadruplex in neutral buffered solution, we discuss the spectrum of the radical cation determined experimentally by photo-ionization of the system in $\mathrm{pH} 3$; under these conditions, deprotonation of $(\mathrm{G})^{+\bullet}$ is hindered, ${ }^{11}$ while the ground state absorption spectrum remains the same as in $\mathrm{pH} 7$ (Figure $\mathrm{S} 3$ ). 


\section{Spectral features}

Experiments at $\mathrm{pH} 3$ : We recorded the spectrum of the (TG4T) ${ }_{4} / \mathrm{Na}^{+}$radical cation at $2.5 \mu \mathrm{s}$ (Figure 3), so that to compare it with that obtained for the G-quadruplex in neutral $\mathrm{pH}$. We also evaluated its molar absorption coefficient assuming that the radical cation concentration matches that of the hydrated electrons $\left[\mathrm{e}^{-}\right]_{0}$, determined as explained in the previous section. The molar absorption coefficient of the (TG4T) $)_{4} / \mathrm{Na}^{+}$radical cation (Figure 3) coincides with that of the monomeric analog at $500 \mathrm{~nm}$, but at $400 \mathrm{~nm}$ it is ca. $40 \%$ lower. A lower intensity of the latter band in respect to the dGMP cation was also found in the case of TEL21/Na ${ }^{+}$(Figure 10 in reference 17). Moreover, the (TG4T) $)_{4} / \mathrm{Na}^{+}$radical cation spectrum is more intense around 600 $\mathrm{nm}$ than those of both dGMP (Figure 3) and TEL21/Na ${ }^{+}$radical cations (Figure S4). Note that the experimental spectrum of the (TG4T) $)_{4} / \mathrm{Na}^{+}$radical cation (Figure 4) is blue shifted compared to that published recently for the same system. ${ }^{26}$ The reason is that, due to a technical failure of the $\mathrm{pH}$-meter, discovered later, the effective $\mathrm{pH}$ value in the previous study was close to 6 .

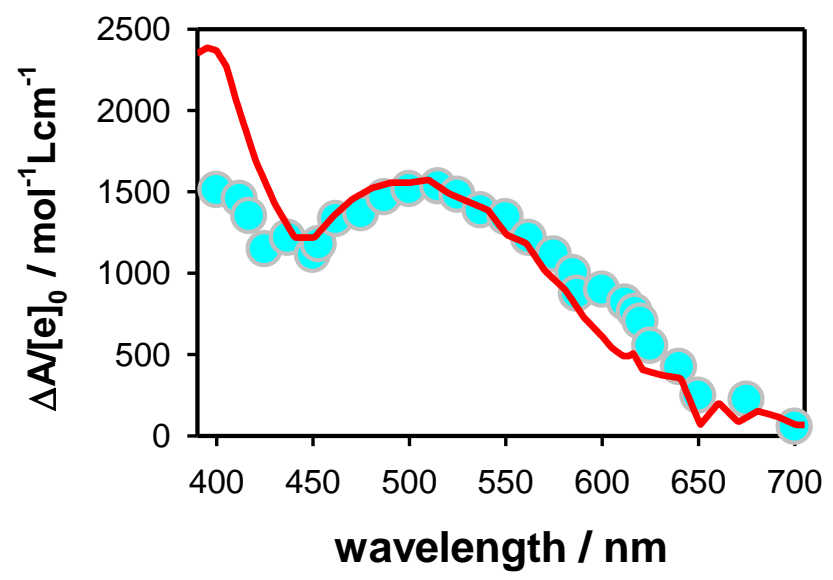

Figure 3. Transient absorption spectrum recorded for $(\mathrm{TG} 4 \mathrm{~T})_{4} / \mathrm{Na}^{+}$in $\mathrm{pH} 3$ at $2.5 \mu$ s (circles); the measured differential absorbance has been divided by the concentration of ejected electrons, determined in the same experiment. Average of three independent experiments. The red line 
corresponds to the spectrum of the radical cation of dGMP, represented with its molar absorption coefficient. $^{46}$

The small but clearly distinguishable feature around $600 \mathrm{~nm}$ in Figure 3 is correlated with delocalization of the electron hole over two guanines occurring for a small part of the population. ${ }^{26}$ Quantum chemical calculations predict that such charge delocalization is possible only for G-quadruplex structures with parallel arrangement but not for antiparallel structures. ${ }^{26,47}$ The spectra computed for (TG4T) $)_{4} / \mathrm{Na}^{+}$bearing localized and delocalized electron holes ${ }^{26}$ and also shown in Figure 4, present clear differences, the latter exhibiting an important band at longer wavelengths.

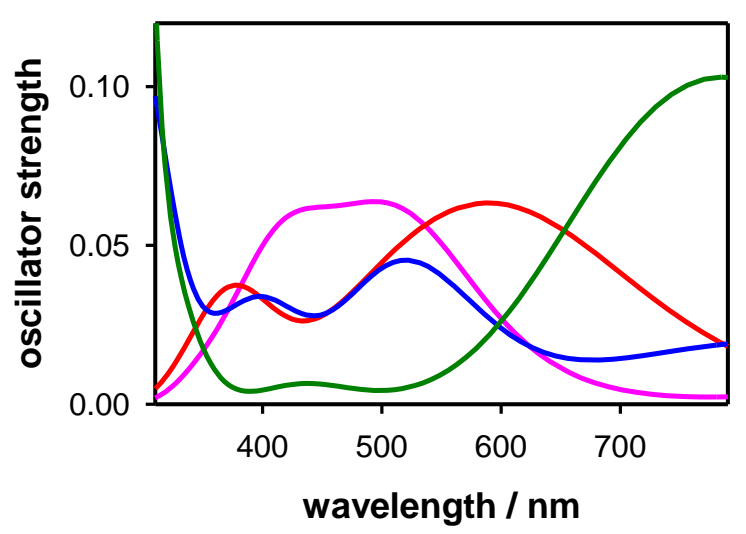

Figure 4. Comparison of the spectra computed for $(\mathrm{TG} 4 \mathrm{~T})_{4} / \mathrm{Na}^{+}$radicals. Pink: radical cation localized on a single guanine ${ }^{26}$; red: radical cation delocalized over two guanines, ${ }^{26}$ green: (G$\mathrm{H} 2)^{\bullet}$ deprotonated radical; blue $(\mathrm{G}-\mathrm{H} 1)^{\bullet}$ deprotonated radical. 
Experiments at $\mathrm{pH} 7$ : The time-resolved absorption spectra of $(\mathrm{TG} 4 \mathrm{~T})_{4} / \mathrm{Na}^{+}$in $\mathrm{pH} 7$ exhibit important evolution during the time. Typical examples are presented in Figure 5; similar spectra, but with increasing experimental error, are obtained at lower excitation intensities when the ratio $\phi_{2} / \phi_{1}$ decreases from 1.7 to 1.2 . At the earliest probed time $(2.5 \mu \mathrm{s})$, the spectrum exhibits a broad band in the visible spectral domain and a more intense one around $300 \mathrm{~nm}$. As time passes by, the relative intensity of the UV band in respect to that in the visible decreases significantly, dropping from 2.5 to 1.5 at $50 \mu$ s. In parallel, the band in the visible becomes narrower and shifts slightly toward the red. The spectrum at $50 \mu$ s strongly resembles that reported in the literature for $(\mathrm{G}-\mathrm{H} 2)^{\bullet}$ radicals of monomeric guanosine derivatives. ${ }^{46,48}$ Thus, we assign it to the $(\mathrm{G}-\mathrm{H} 2)^{\bullet}$ radical. Further transformations take place in the ms time-scale. At $6 \mathrm{~ms}$, the spectral profile has completely changed. We now distinguish three bands of decreasing intensity, peaking at 315 , 400 and $515 \mathrm{~nm}$, as reported for the $(\mathrm{G}-\mathrm{H} 1)^{\bullet}$ radical of dGMP. ${ }^{46,49}$

From the above observations, we can already draw a rough picture of the successive events taking place on the probed time-scale. First, we have a mixture of the radical cation and the deprotonated radical $(\mathrm{G}-\mathrm{H} 2)^{\bullet}$. After completion of the deprotonation process, only $(\mathrm{G}-\mathrm{H} 2)^{\bullet}$ radicals are present. Finally, at least part of the latter radicals, undergoes tautomerisation, giving rise to $(\mathrm{G}-\mathrm{H} 1)^{\bullet}$ radicals. These assignments are supported by the comparative spectra computed for the various (TG4T) ${ }_{4} / \mathrm{Na}^{+}$radicals, shown in Figure 4. The most intense band in the red is indeed exhibited by $(\mathrm{G}-\mathrm{H} 2)^{\bullet}$, located close to that of the delocalized radical cation. The spectrum of (G-H1) $)^{\bullet}$ is characterized by two bands which are blue-shifted in respect that of $(\mathrm{G}-\mathrm{H} 2)^{\bullet}$; weaker transitions, located at lower energies could be responsible for the important red tail observed experimentally (Figure 5c), as in the case of the guanine deprotonated radical cations in alternating GC duplexes. ${ }^{19}$ 
As mentioned previously, the important width of the absorption band observed at $2.5 \mu$ s for $(\mathrm{TG} 4 \mathrm{~T})_{4} / \mathrm{Na}^{+}$in $\mathrm{pH} 7$ suggests the coexistence of the radical cation and the $(\mathrm{G}-\mathrm{H} 2)^{\bullet}$ deprotonated radical. In order to quantify the relative concentrations of these species, we constructed linear combinations of the spectra corresponding to the radical cation (Figure 3,2.5 $\mu \mathrm{s}$ ) and the deprotonated radical $(\mathrm{G}-\mathrm{H} 2)^{\bullet}$ (Figure $5 \mathrm{~b}$ ); for the latter spectrum we used the molar absorption coefficient reported for the monomeric radical. The linear combination corresponding to $25 \%$ of radical cation (precision $\pm 5 \%$ ), shown in Figure 5a, provides a good agreement, not only for the spectral shape but also for the spectral intensity (right axis in $\Delta \mathrm{A} /\left[\mathrm{e}^{-}\right]_{0}$ ).
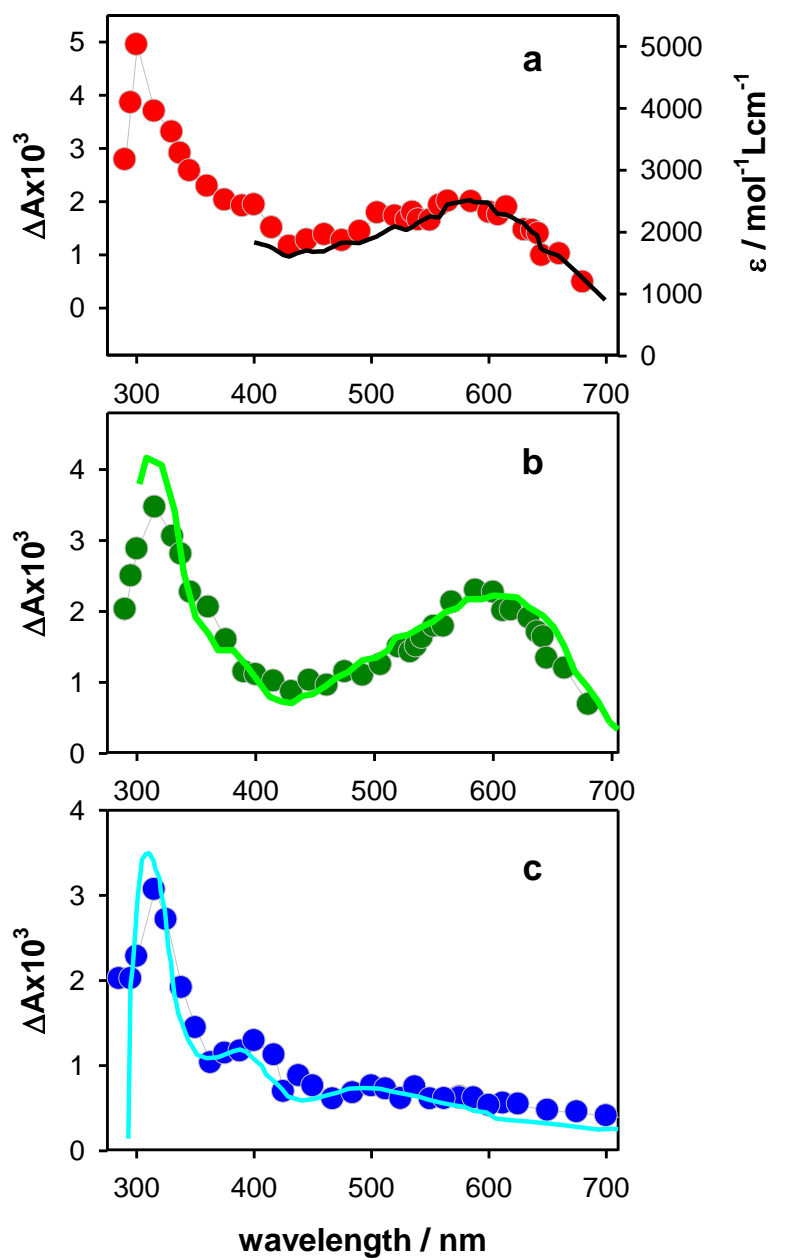
Figure 5. Transient absorption spectra recorded for (TG4T) $)_{4} / \mathrm{Na}^{+}$in pH 7 (circles) at $2.5 \mu \mathrm{s}$ (a), $50 \mu \mathrm{s}$ (b) and $6 \mathrm{~ms}$ (c). Excitation intensity: $2 \mathrm{MWcm}^{-2}$. The black line in (a) is a linear combination of the (TG4T) $)_{4} / \mathrm{Na}^{+}$spectra corresponding to its radical cation (Figure 3) and the $(\mathrm{G}-\mathrm{H} 2)^{\bullet}$ deprotonated radical (Figure $5 \mathrm{~b}$ ) at a ratio 25:75. The green (b) and cyan (c) lines correspond, respectively, to the spectra of $(\mathrm{G}-\mathrm{H} 2)^{\bullet}{ }^{48}$ and $(\mathrm{G}-\mathrm{H} 1)^{\bullet}{ }^{46}$ radicals of monomeric guanosine, their intensity being arbitrarily normalized in respect to that of the G-quadruplex spectra.

\section{Dynamical features}

Typical examples of radical kinetics, determined at 500 and $600 \mathrm{~nm}$, are shown in Figure 6. On the $\mu$ s time-scale, we observe that the differential absorbance at $500 \mathrm{~nm}$ decreases while that at $600 \mathrm{~nm}$ rises. The signals can be described by single exponential functions, $\mathrm{B}_{1} \exp \left(-\mathrm{t} / \tau_{2}\right)+\mathrm{B}_{0}$ and $\mathrm{B}_{1}\left(1-\exp \left(-\mathrm{t} / \tau_{2}\right)\right)+\mathrm{B}_{0}$, for the decrease and the rise, respectively, with the same time constant of $5 \pm$ $1 \mu$ s. In view of our spectral analysis (Figure 5a), we assign the decay to the deprotonation of the radical cation and the rise to the formation of the $(\mathrm{G}-\mathrm{H} 2)^{\bullet}$ radical. The decays recorded on the ms time-scale can be described by two-exponential functions $\mathrm{C}_{1} \exp \left(-\mathrm{t} / \tau_{3}\right)+\mathrm{C}_{2} \exp \left(-\mathrm{t} / \tau_{4}\right)+\mathrm{C}_{0}$ with time constants of $2.6 \pm 0.2$ and $21 \pm 2 \mathrm{~ms}$. The latter are dominated by the disappearance of (G-H2) and $(\mathrm{G}-\mathrm{H} 1)^{\bullet}$ radicals, respectively, as suggested by the time-resolved spectra in Figures $6 \mathrm{~b}$ and $6 c$.

The time constants derived from the fits in Figure 6 do not necessarily correspond to "absolute lifetimes" of the various radicals. As largely documented in the literature, reaction kinetics in anisotropic structures follow non-exponential patterns that may extend over several decades of time (see for example references ${ }^{50}$ and ${ }^{51}$ ). In G-quadruplexes, guanine radicals have different local environments, depending, for instance, on their location in inner or outer tetrads. The 
picture is further complicated by dynamical disorder, related to continuous conformational changes, ${ }^{52}$ as well as to motions of the $\mathrm{Na}^{+}$cations in the central cavity, occurring on the millisecond time-scale. ${ }^{53}$ It is worth-noticing that the fluorescence decays of G-quadruplexes, probed over several orders of magnitude of time, also exhibits clearly multiscale decays (Figure 5 in reference $\left.{ }^{54}\right)$.
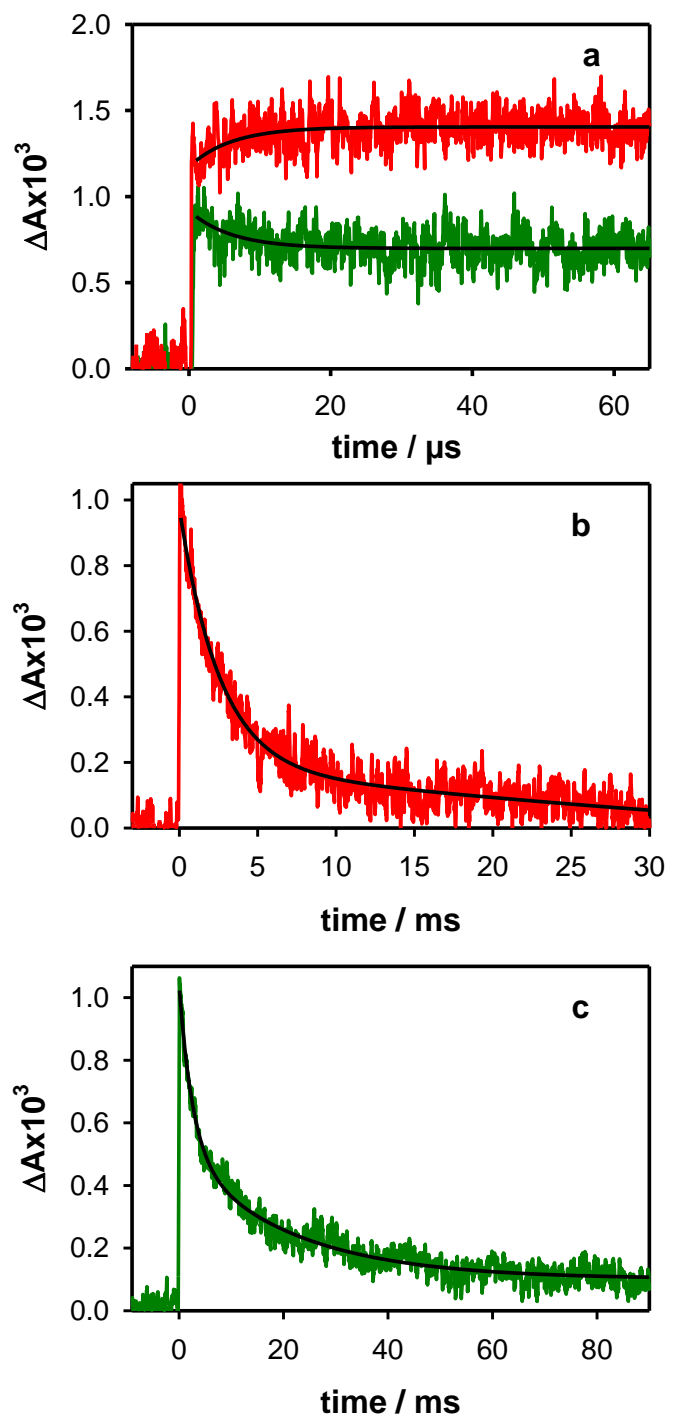
Figure 6. Normalized transient absorption signals recorded for (TG4T) $)_{4} / \mathrm{Na}^{+}$at $500 \mathrm{~nm}$ (green) and $600 \mathrm{~nm}$ (red) at various time scales. Black lines correspond to fits with mono-exponential (a; time constant $6 \mu \mathrm{s}$ ) and bi-exponential (b and c; time constants 2.6 and $21 \mathrm{~ms}$ ) functions.

The non-exponential kinetics of the $(\mathrm{TG} 4 \mathrm{~T})_{4} / \mathrm{Na}^{+}$radicals can be easily illustrated by the behavior of $(\mathrm{G})^{+\bullet}$. If the entire population of radical cations was decaying with the time constant of $5 \pm 1 \mu$ s (Figure 6a), 67\% should survive at $2.5 \mu \mathrm{s}$; but the spectra in Figure 5a indicate the presence of only $25 \%$. This means that the major part of the radical cation population undergoes rapid deprotonation and our measurements on the $\mu$ s time-scale detect only the slower part of the process. This non-exponentiality is even more pronounced in the case of TEL21/Na ${ }^{+}$, for which half of the radical cation population deprotonates on the millisecond time-scale while the other half before $3 \mu \mathrm{s} .^{17}$

Deprotonation of $25 \%$ of the radical cations in (TG4T) ${ }_{4} / \mathrm{Na}^{+}$is completed within around $20 \mu \mathrm{s}$ (Figure 6a). Based on the spectra in Figure 5b and using a molar absorption coefficient of 2100 $\mathrm{mol}^{-1} \mathrm{Lcm}^{-1}$ at $600 \mathrm{~nm}$, determined for monomeric $(\mathrm{G}-\mathrm{H} 2)^{\bullet}$ radicals, ${ }^{46,}{ }^{48}$ we find that their concentration matches that of the ejected electrons. This means that the entire $(\mathrm{G})^{+\bullet}$ population undergoes deprotonation, other types of reactions being negligible. This conclusion is confirmed by the lack of formation of 8-oxo-7,8-dihydro-2' -deoxyguanosine (8-oxodGuo) in (TG4T) ${ }_{4} / \mathrm{Na}^{+}$ samples irradiated at $266 \mathrm{~nm}$ by a continuous light source. As a matter of fact, 8-oxoGuo is a well-known reaction product issued from $(\mathrm{G})^{+\bullet}, 55$ whose quantitative determination may be achieved by mass spectrometry coupled to liquid chromatography. Such an analytical procedure, described in the Supporting Information, did not reveal any detectable formation of 8-oxodGuo. 
This shows that the corresponding quantum yield does not exceed $10^{-5}$, which is two orders of magnitude lower that of the one-photon ionization yield $\left(3.5 \times 10^{-3}\right)$.

Using a value of $1500 \mathrm{~mol}^{-1} \mathrm{Lcm}^{-1}$ for the molar absorption coefficient of $(\mathrm{G}-\mathrm{H} 1)^{\bullet}$ at $500 \mathrm{~nm},{ }^{46}$ we find that when the $(\mathrm{G}-\mathrm{H} 2)^{\bullet} \rightarrow(\mathrm{G}-\mathrm{H} 1)^{\bullet}$ tautomerisation is completed, within around $10 \mathrm{~ms}$, only $40 \%$ of the initial radical population survives. Such a population is too low assuming that $(\mathrm{G}-\mathrm{H} 2)^{\bullet}$ disappears according a mono-exponential decay pattern and $(\mathrm{G}-\mathrm{H} 1)^{\bullet}$ is formed also following a mono-exponential law. Besides the non-exponentiality of the process discussed above, another reason for the latter discrepancy could also be related to other reaction products formed directly from $(\mathrm{G}-\mathrm{H} 2)^{\bullet}$ radicals. In our knowledge, the reactivity of $(\mathrm{G}-\mathrm{H} 2)^{\bullet}$ radicals has not been explored so far.

Table 1. Types of UV-induced guanine radicals in $(\mathrm{TG} 4 \mathrm{~T})_{4} / \mathrm{Na}^{+}$at selected times; their populations are given as fractions of the initial concentration of detected hydrated electrons. Estimated error: \pm 0.05 . In brackets: values corresponding to TEL21/ $\mathrm{Na}^{+}{ }^{17}$

\begin{tabular}{llll} 
time & $(\mathrm{G})^{+\bullet}$ & $(\mathrm{G}-\mathrm{H} 2)^{\bullet}$ & $(\mathrm{G}-\mathrm{H} 1)^{\bullet}$ \\
\hline $2 \mu \mathrm{s}$ & $0.25[0.50]$ & $0.75[0.50]$ & - \\
$50 \mu \mathrm{s}$ & $0.00[0.35]$ & $1.02[0.50]$ & - \\
$10 \mathrm{~ms}$ & 0.00 & 0.00 & 0.40 \\
$180 \mathrm{~ms}$ & 0.00 & 0.00 & $0.05[0.06]$
\end{tabular}

The populations of the various (TG4T) ${ }_{4} / \mathrm{Na}^{+}$and TEL21/Na ${ }^{+}$radicals present at selected times, expressed as a molar fractions of the hydrated electron concentration, are shown in Table 1. Table 2 presents the time constants derived from the fits with exponential functions. Despite the lack of physical meaning of such fits, as they were performed over the same time domain, they 
allow comparison between the behaviour of the two G-quadruplex scaffolds, when discussed in association with the populations in Table 1.

The most striking difference in the behaviour of the two types of G-quadruplexes resides in the deprotonation dynamics of their cations. In view of both the population fractions surviving at 2 $\mu$ s for $(\mathrm{TG} 4 \mathrm{~T})_{4} / \mathrm{Na}^{+}$and TEL21/Na ${ }^{+}(0.25$ vs 0.50$)$ and the time constants determined for the slowest part of the deprotonation ( $5 \mu \mathrm{s}$ vs $1.2 \mathrm{~ms}$ ), it is clear that the deprotonation process is much more rapid for the tetramolecular structure. The considerably shorter lifetime of $(\mathrm{TG} 4 \mathrm{~T})_{4} / \mathrm{Na}^{+}$radical cations could account for the absence of 8-oxodGuo formation. In contrast, $7 \%$ of the longer living TEL21/ $\mathrm{Na}^{+}$radical cations are transformed to 8 -oxodGuo. ${ }^{17}$ These dynamical features may also be correlated with energetic factors. The energy difference corresponding to $(\mathrm{G})^{+\bullet} \rightarrow(\mathrm{G}-\mathrm{H} 2)^{\bullet}$ process computed at the QM/MM level for TEL21/ $\mathrm{Na}^{+}$is twice as high as that of (TG4T) $)_{4} / \mathrm{Na}^{+}$(Table 2), in qualitative agreement with faster deprotonation observed for the latter system. It is also worth noticing that according to Table 2, delocalization of the electron hole should increase its lifetime.

Table 2. Lifetimes of guanine radicals determined experimental for two different G-quadruplex scaffolds. In brackets: computed energy difference, in $\mathrm{kcal} \mathrm{mol}^{-1}$, corresponding to the deprotonation and tautomerisation processes. An energy of $-262 \mathrm{kcal} \mathrm{mol}^{-1}$ is taken for the $\mathrm{H}^{+}$in aqueous solution. ${ }^{56}$

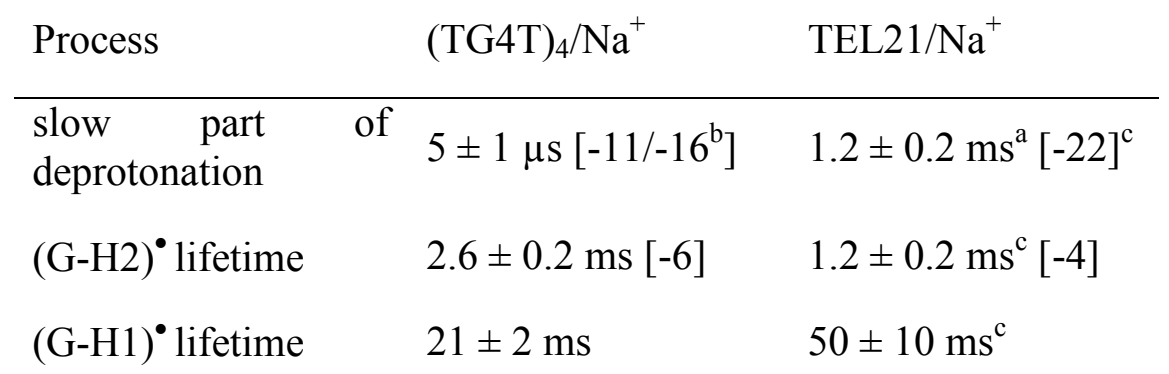


${ }^{a}$ From reference ${ }^{17}$; ${ }^{b}$ localized/delocalized radical cations; ${ }^{c}$ different values from those in reference ${ }^{17}$ due to the different number of tetrads considered in the present QM model (3 instead of 2).

Contrary to deprotonation, the $(\mathrm{G}-\mathrm{H} 2)^{\bullet} \rightarrow(\mathrm{G}-\mathrm{H} 1)^{\bullet}$ tautomerisation is slower for $(\mathrm{TG} 4 \mathrm{~T})_{4} / \mathrm{Na}^{+}$ compared to TEL21/ $\mathrm{Na}^{+}$(Table 1). The dynamics of this process could be associated with the relative stability of the two types of deprotonated radicals within each system. In this case, the energy difference between $(\mathrm{G}-\mathrm{H} 2)^{\bullet}$ and $(\mathrm{G}-\mathrm{H} 1)^{\bullet}$ radicals computed for $(\mathrm{TG} 4 \mathrm{~T})_{4} / \mathrm{Na}^{+}$is twice as high as that found for TEL21/ $\mathrm{Na}^{+}$(Table 2). Finally, the lifetime of the (G-H1) found for (TG4T) ${ }_{4} / \mathrm{Na}^{+}$is shorter than that determined for TEL21/Na ${ }^{+}$(Table 2). We explain this difference by the stability of the "normal", non-photo-ionized, G-quadruplex scaffolds, reflected in their melting curves. Under the same buffer conditions, the melting temperature of TEL21/ $\mathrm{Na}^{+}$ is $77^{\circ} \mathrm{C}^{17}$ while it is only $60^{\circ} \mathrm{C}$ for $(\mathrm{TG} 4 \mathrm{~T})_{4} / \mathrm{Na}^{+}$(Figure SI-1).

\section{CONCLUSION}

The first important conclusion of the present study is that, like other DNA oligomers with pronounced secondary structure, (TG4T) $)_{4} / \mathrm{Na}^{+}$undergoes one-photon ionization at an energy lower by $2.7 \mathrm{eV}$ than the ionization potential of nucleobases. The associated quantum yield $\left(3.5 \times 10^{-3}\right)$ is about three times higher than those reported previously for duplexes $(18-20,41)$ but $20 \%$ lower than that of TEL21/ $\mathrm{Na}^{+}{ }^{17}$ At the present state of knowledge, we cannot explain the different propensity of the various DNA strands in aqueous solution to undergo electron detachment upon irradiation with low-energy photons because the underlying mechanism is not known. Possible correlation with population of charge transfer states involving different bases has been mentioned; such a scenario would imply charge separation, charge migration steps and electron ejection from a radical anion. ${ }^{20} \mathrm{~A}$ quite recent theoretical study reports that $\pi \sigma^{*}$ bonds may play a role in the photo-ionization process. ${ }^{57}$ One could also imagine that the local structure 
and dynamics of water molecules are responsible for the decrease of the vertical ionization potential of a small fraction of nucleobases. ${ }^{58}$ Collection of more experimental data, which is delicate and slow, combined to theoretical studies, is necessary in order to privilege one of these hypotheses.

Our second conclusion concerns the types of guanine radicals generated by photo-ionization; probed from $2 \mu \mathrm{s}$ to $2 \mathrm{~ms}$, they appear in the order $(\mathrm{G})^{+\cdot},(\mathrm{G}-\mathrm{H} 2)^{\bullet}$ and $(\mathrm{G}-\mathrm{H} 1)^{\bullet}$. In connection with theoretical studies, ${ }^{26,47}$ the spectrum of the radical cation indicates weak delocalization of the positive charge. In contrast, the spectrum of the deprotonated radical is practically identical to that of monomeric guanosine, both in intensity and in shape. ${ }^{48}$ In fact, the experimental spectra of the radicals correspond to an average associated with highly anisotropic structures. Combination of quantum mechanical methods with molecular dynamics simulations should bring subtle information regarding the effect of local environment of radicals on their spectral properties.

The survival probabilities of the various (TG4T) ${ }_{4} / \mathrm{Na}^{+}$radicals exhibit important differences compared to those determined previously for the TEL21/ $\mathrm{Na}^{+}$radicals. ${ }^{17}$ (i) Deprotonation of the radical cations is much faster, this behavior having been correlated to their lower reactivity towards 8-oxodGuo formation. (ii) The $(\mathrm{G}-\mathrm{H} 2)^{\circ} \rightarrow(\mathrm{G}-\mathrm{H} 1)^{\bullet}$ taumerisation is slower, and (iii) the lifetime of $(\mathrm{G}-\mathrm{H} 1)^{\bullet}$ is shorter. Such a comparison between tetramolecular and monomolecular Gquadruplexes formed in the presence of $\mathrm{Na}^{+}$ions, brought light to the effect of topology on the radical properties. It would be important to examine if these trends persist for other couples of parallel/antiparallel structures. And, furthermore, examine the effect of the metal ions located in the central cavity of the G-quadruplex scaffolds. 
We note that we found no report in the literature on direct UV-induced reactions of tetramolecular G-quadruplexes. Thus, the reaction products resulting from the two types of deprotonated radicals in (TG4T) $4{ }_{4} / \mathrm{Na}^{+}$remain to be determined.

\section{ASSOCIATED CONTENT}

\section{Supporting Information.}

The following file is available free of charge.

1. Melting curve, 2. Computational model, 3. Steady state-absorption spectra, 4. Comparison of various $(\mathrm{G})^{+\bullet}$ absorption spectra, 5. Continuous light irradiations and photoproduct analysis. (PDF)

\section{AUTHOR INFORMATION}

\section{Corresponding Author}

* (D. M.) E-mail: dimitra.markovitsi@cea.fr, Telephone: +33169084644

\section{ORCID}

Akos Banyasz: 0000-0002-2412-3019

Evangelos Balanikas: 0000-0002-2811-1525

Lara Martinez-Fernandez: 0000-0001-5361-9390

Gérard Baldacchino: : 0000-0002-4126-6003

Thierry Douki: 000000025022071X

Roberto Improta: 0000-0003-1004-195X 
Dimitra Markovitsi: 0000-0002-2726-305X

\section{Author Contributions}

The manuscript was written through contributions of all authors. All authors have given approval to the final version of the manuscript.

\section{ACKNOWLEGDEMENTS}

\section{Funding Sources}

This work has received funding from the European Union's Horizon 2020 research and innovation programme under the Marie Sklodowska-Curie grant agreement No. 765266 (LightDyNAmics). It was also supported by the French National Research Agency [N ${ }^{\circ}$ ANR-12BS08-0001-01, OPHID project]; Investissements d'Avenir LabEx PALM [ANR-10-LABX0039-PALM]; Université Paris Saclay - programme D’Alembert 2016, $N^{\circ} 10751$. and the European Programme H2020 MSCA ITN [grant No. 765266 - LightDyNAmics project] and used HPC resources from GENCI-IDRIS [Grant 2017-A0030810262].

\section{Notes}

The authors declare no competing financial interest.

\section{REFERENCES}

1. Plavec, J.; Sket, P., Diversity of DNA and RNA G-quadruplex structures. In Biological Relevance \& Therapeutic Applications of DNA- \& RNA-Quadruplexes, Monchaud, D., Ed. Future Medicine Ltd,: London, 2015; pp 22-36.

2. Lipps, H. J.; Rhodes, D., G-quadruplex structures: in vivo evidence and function. Trends Cell Biol. 2009, 19 (8), 414-422.

3. Biffi, G.; Tannahill, D.; McCafferty, J.; Balasubramanian, S., Quantitative visualization of DNA Gquadruplex structures in human cells. Nature Chem. 2013, 5 (3), 182-186.

4. Rhodes, D.; Lipps, H. J., G-quadruplexes and their regulatory roles in biology. Nucleic Acids Res. 2015, 43 (18), 8627-8637. 
5. Livshits, G. I.; Stern, A.; Rotem, D.; Borovok, N.; Eidelshtein, G.; Migliore, A.; Penzo, E.; Wind, S. J.; Di Felice, R.; Skourtis, S. S.; Carlos Cuevas, J.; Gurevich, L.; Kotlyar, A. B.; Porath, D., Long-range charge transport in single G-quadruplex DNA molecules. Nature Nanotech. 2014, 9 (12), 1040-1046.

6. Sha, R. J.; Xiang, L. M.; Liu, C. R.; Balaeff, A.; Zhang, Y. Q.; Zhang, P.; Li, Y. Q.; Beratan, D. N.; Tao, N. J.; Seeman, N. C., Charge splitters and charge transport junctions based on guanine quadruplexes. Nature Nanotech. 2018, 13 (4), 316-+.

7. Fleming, A. M.; Ding, Y.; Burrows, C. J., Oxidative DNA damage is epigenetic by regulating gene transcription via base excision repair. Proc. Natl. Acad. Sci. USA 2017, 114 (10), 2604-2609.

8. Fouquerel, E.; Lormand, J.; Bose, A.; Lee, H. T.; Kim, G. S.; Li, J. F.; Sobol, R. W.; Freudenthal, B. D.; Myong, S.; Opresko, P. L., Oxidative guanine base damage regulates human telomerase activity. Nat. Struct. Mol. Biol. 2016, 23 (12), 1092-1100.

9. Thazhathveetil, A. K.; Harris, M. A.; Young, R. M.; Wasielewski, M. R.; Lewis, F. D., Efficient Charge Transport via DNA G-Quadruplexes. J. Am. Chem. Soc. 2017, 139 (5), 1730-1733.

10. Choi, J.; Park, J.; Tanaka, A.; Park, M. J.; Jang, Y. J.; Fujitsuka, M.; Kim, S. K.; Majima, T., Hole Trapping of G-Quartets in a G-Quadruplex. Angew. Chem. Int. Ed. 2013, 52 (4), 1134-1138.

11. Candeias, L. P.; Steenken, S., Ionization of purine nucleosides and nucleotides and their components by 193-nm laser photolysis in aqueous solution: model studies for oxidative damage of DNA. J. Am. Chem. Soc. 1992, 114, 699-704.

12. Kobayashi, K.; Tagawa, S., Direct observation of guanine radical cation deprotonation in duplex DNA using pulse radiolysis. J. Am. Chem. Soc. 2003, 125 (34), 10213-10218.

13. Adhikary, A.; Kumar, A.; Becker, D.; Sevilla, M. D., The guanine cation radical: investigation of deprotonation states by ESR and DFT. J. Phys. Chem. B 2006, 110 (47), 24171-24180.

14. Cadet, J.; Douki, T.; Ravanat, J. L., Oxidatively generated damage to the guanine moiety of DNA: Mechanistic aspects and formation in cells. Acc. Chem. Res. 2008, 41 (8), 1075-1083.

15. Cadet, J.; Douki, T.; Ravanat, J.-L., Oxidatively Generated Damage to Cellular DNA by UVB and UVA Radiation. Photochem. Photobiol. 2015, 91 (1), 140-155.

16. Wu, L. D.; Liu, K. H.; Jie, J. L.; Song, D.; Su, H. M., Direct Observation of Guanine Radical Cation Deprotonation in G-Quadruplex DNA. J. Am. Chem. Soc. 2015, 137 (1), 259-266.

17. Banyasz, A.; Martinez-Fernandez, L.; Balty, C.; Perron, M.; Douki, T.; Improta, R.; Markovitsi, D., Absorption of Low-Energy UV Radiation by Human Telomere G-Quadruplexes Generates Long-Lived Guanine Radical Cations. J. Am. Chem. Soc. 2017, 139 (30), 10561-10568.

18. Schroeder, C. A.; Pluharova, E.; Seidel, R.; Schroeder, W. P.; Faubel, M.; Slavicek, P.; Winter, B.; Jungwirth, P.; Bradforth, S. E., Oxidation Half-Reaction of Aqueous Nucleosides and Nucleotides via Photoelectron Spectroscopy Augmented by ab Initio Calculations. J. Am. Chem. Soc. 2015, 137 (1), 201209.

19. Banyasz, A.; Martinez-Fernandez, L.; Improta, R.; Ketola, T. M.; Balty, C.; Markovitsi, D., Radicals generated in alternating guanine-cytosine duplexes by direct absorption of low-energy UV radiation. Phys. Chem. Chem. Phys. 2018, 20 (33), 21381-21389.

20. Banyasz, A.; Ketola, T.; Martinez-Fernandez, L.; Improta, R.; Markovitsi, D., Adenine radicals generated in alternating AT duplexes by direct absorption of low-energy UV radiation. Faraday Disc. 2018, 207, 181-197.

21. Banyasz, A.; Ketola, T.; Muñoz-Losa, A.; Rishi, S.; Adhikary, A.; Sevilla, M. D.; MartinezFernandez, L.; Improrta, R.; Markovitsi, D., UV-induced Adenine Radicals Induced in DNA A-tracts: Spectral and Dynamical Characterization J. Phys. Chem. Lett. 2016, 7, 3949-3953.

22. Burge, S.; Parkinson, G. N.; Hazel, P.; Todd, A. K.; Neidle, S., Quadruplex DNA: sequence, topology and structure. Nucleic Acids Res. 2006, 34 (19), 5402-5415.

23. Burge, S.; Parkinson, G. N.; Hazel, P.; Todd, A. K.; Neidle, S., Quadruplex DNA: sequence, topology and structure. Nucl. Ac. Res. 2006, 34 (19), 5402-5415. 
24. Visscher, K. J.; Dehaas, M. P.; Loman, H.; Vojnovic, B.; Warman, J. M., Fast protonation of adenosine and of its radical anion formed by hydrated electon attack - a nanosecond optical and DCconductivity pulse-radiolysis study. Int. J. Rad. Biol. 1987, 52 (5), 745-753.

25. Ma, J.; Wang, F.; Denisov, S. A.; Adhikary, A.; Mostafavi, M., Reactivity of prehydrated electrons toward nucleobases and nucleotides in aqueous solution. Sci. Adv. 2017, 3 (12), e1701669.

26. Martinez-Fernandez, L.; Banyasz, A.; Markovitsi, D.; Improta, I., Topology controls the electronic absorption delocalization of electron hole in guanine quadruplexes. Chem. Europ. J. 2018, 24, 1518515189.

27. Mergny, J. L.; Phan, A. T.; Lacroix, L., Following G-quartet formation by UV-spectroscopy. Febs Letters 1998, 435 (1), 74-78.

28. Amand, B.; Bensasson, R., Determination of triplet quantum yields by laser flash absorption spectroscopy. Chem. Phys. Lett. 1975, 34 (1), 44-48.

29. Zhao, Y.; Schultz, N. E.; Truhlar, D. G., Design of density functionals by combining the method of constraint satisfaction with parametrization for thermochemistry, thermochemical kinetics, and noncovalent interactions. J. Chem. Theory Comput. 2006, 2 (2), 364-382.

30. Zhao, Y.; Truhlar, D. G., Density functionals with broad applicability in chemistry. Acc. Chem. Res. 2008, 41 (2), 157-167.

31. Improta, R.; Barone, V., Excited states behavior of nucleobases in solution: insights from computational studies. Top. Curr. Chem. 2015, 355, 329-57.

32. Improta, R.; Santoro, F.; Blancafort, L., Quantum Mechanical Studies on the Photophysics and the Photochemistry of Nucleic Acids and Nucleobases. Chem. Rev. 2016, 116 (6), 3540-3593.

33. Cornell, W. D.; Cieplak, P.; Bayly, C. I.; Gould, I. R.; Merz, K. M.; Ferguson, D. M.; Spellmeyer, D. C.; Fox, T.; Caldwell, J. W.; Kollman, P. A., A 2nd generation force-field for the simulation of proteins, nucleic acids, and organic molecules. J. Am. Chem. Soc. 1995, 117 (19), 5179-5197.

34. Dapprich, S.; Komaromi, I.; Byun, K. S.; Morokuma, K.; Frisch, M. J., A new ONIOM implementation in Gaussian98. Part I. The calculation of energies, gradients, vibrational frequencies and electric field derivatives. J. Mol. Struct.-Theochem 1999, 461, 1-21.

35. Miertus, S.; Scrocco, E.; Tomasi, J., Electrostatic interaction of a solute with a continuum - A direct utilization of abinitio molecular potentials for the prevision of solvent effects Chem. Phys. 1981, 55 (1), 117-129.

36. Tomasi, J.; Mennucci, B.; Cammi, R., Quantum mechanical continuum solvation models. Chem. Rev. 2005, 105 (8), 2999-3093.

37. Laughlan, G.; Murchie, A. I. H.; Norman, D. G.; Moore, M. H.; Moody, P. C. E.; Lilley, D. M. J.; Luisi, B., The high-resolution crystal-structure of parallel-stranded guanine tetraplex. Science 1994, 265 (5171), 520-524.

38. Kumar, A.; Sevilla, M. D., Excited States of One-Electron Oxidized Guanine-Cytosine Base Pair Radicals: A Time Dependent Density Functional Theory Study. J. Phys. Chem. A 2019, 123 (14), 30983108.

39. Torche, F.; Marignier, J. L., Direct Evaluation of the Molar Absorption Coefficient of Hydrated Electron by the Isosbestic Point Method. J. Phys. Chem. B 2016, 120 (29), 7201-7206.

40. Gauduel, Y.; Migus, A.; Chambaret, J. P.; Antonetti, A., Femtosecond Reactivity of Electron in Aqueous Solutions. Rev. Phys. Appl. 1987, 22 (12), 1755-1759.

41. Buxton, G. V.; Greenstock, C. L.; Helman, W. P.; Ross, A. B., Critical review of rate constants for reactions of hydrated electrons, hydrogen atoms and hydroxyl radicals (.OH/O.-) in aqueous solution. J. Phys.Chem. Ref. Data 1988, 17, 513-886.

42. Nikogosyan, D. N.; Oraevsky, A. A.; Letokhov, V. S.; Arbieva, Z. K.; Dobrov, E. N., Two-step picosecond UV excitation of polynucleotides and energy transfer. Chem. Phys. 1985, 97, 31-41. 
43. Görner, H., Photochemistry of DNA and related biomolecules: quantum yields and consequences of photoionization. J. Photochem. Photobiol. B: Biol. 1994, 26, 117-139.

44. Crespo-Hernandez, C. E.; Arce, R., Near threshhold photo-oxidation of dinucleotides containing purines upon $266 \mathrm{~nm}$ nanosecond laser excitation. The role of base stacking, conformation and sequence. J. Phys. Chem. B 2003, 107, 1062-1070.

45. Marguet, S.; Markovitsi, D.; Talbot, F., One and two photon ionization of DNA single and double helices studied by laser flash photolysis at $266 \mathrm{~nm}$. J. Phys. Chem. B 2006, 110, 11037-11039.

46. Candeias, L. P.; Steenken, S., Stucture and acid-base properties of one-electron-oxidized deoxyguanosine, guanosine, and 1-methylguanosine. J. Am. Chem. Soc. 1989, 111, 1094-1099.

47. Sun, W. M.; Varsano, D.; Di Felice, R., Effects of G-Quadruplex Topology on Electronic Transfer Integrals. Nanomaterials 2016, 6 (10).

48. Chatgilialoglu, C.; Caminal, C.; Altieri, A.; Vougioukalakis, G. C.; Mulazzani, Q. G.; Gimisis, T.; Guerra, M., Tautomerism in the guanyl radical. J. Am. Chem. Soc. 2006, 128 (42), 13796-13805.

49. Rokhlenko, Y.; Cadet, J.; Geacintov, N. E.; Shafirovich, V., Mechanistic Aspects of Hydration of Guanine Radical Cations in DNA. J. Am. Chem. Soc. 2014, 136 (16), 5956-5962.

50. Blumen, A.; Klafter, J.; Zumofen, G., Models for reaction dynamics in glasses. In Optical spectroscopy of glasses, Zschokke, I., Ed. Reidel Publishing Co.: 1986; pp 199-265.

51. Cichos, F.; von Borczyskowski, C.; Orrit, M., Power-law intermittency of single emitters. Curr. Opin. Colloid Interface Sci. 2007, 12 (6), 272-284.

52. Cragnolini, T.; Chakraborty, D.; Sponer, J.; Derreumaux, P.; Pasquali, S.; Wales, D. J., Multifunctional energy landscape for a DNA G-quadruplex: An evolved molecular switch. J. Chem. Phys. 2017, 147 (15).

53. Sket, P.; Plavec, J., Tetramolecular DNA Quadruplexes in Solution: Insights into Structural Diversity and Cation Movement. J. Am. Chem. Soc. 2010, 132 (36), 12724-12732.

54. Changenet-Barret, P.; Hua, Y.; Gustavsson, T.; Markovitsi, D., Electronic excitations in Gquadruplexes formed by the human telomeric sequence: a time-resolved fluorescence study. Photochem. Photobiol. 2015, 91, 759-765.

55. Kasai, H.; Yamaizumi, Z.; Berger, M.; Cadet, J., Photosynsitized formation of 7,8-dihydro-8-oxo2'-deoxoguanosine (8-hydroxy-2'-deoxoguanosine) in DNA by riboflavin - a non singlet oxygen mediated reaction. J. Am. Chem. Soc. 1992, 114 (24), 9692-9694.

56. Tawa, G. J.; Topol, I. A.; Burt, S. K.; Caldwell, R. A.; Rashin, A. A., Calculation of the aqueous solvation free energy of the proton. J. Chem. Phys. 1998, 109 (12), 4852-4863.

57. Karsili, T. N. V.; Marchetti, B.; Ashfold, M. N. R., The role of (1)pi sigma* states in the formation of adenine radical-cations in DNA duplexes. Chem. Phys. 2018, 515, 464-471.

58. Laage, D.; Elsaesser, T.; Hynes, J. T., Water Dynamics in the Hydration Shells of Biomolecules. Chem. Rev. 2017, 117 (16), 10694-10725. 